https://www.amerabra.org; https://fspu.uitm.edu.my/cebs; https://www.emasemasresources.com 9th Asia Pacific International Conference on Environment-Behaviour Studies,

Faculty of Architecture, Ulisboa, Lisbon, Portugal, 03-04 Jul 2019

\title{
A Proposal for the Definition of Housing with EXPRESS
}

\author{
Emrah Turkyilmaz, Semih Bayer
}

İstanbul Kültür University, 34158, Bakırköy, İstanbul, Turkey

e.turkyilmaz@iku.edu.tr,semihbayer@outlook.com

Tel: +905325686911

\begin{abstract}
This article describes how to use the EXPRESS language for the definition of an architectural product. To make this definition, EXPRESS language and ISO 10303 standards examined. A housing project in the BIM environment described as an example by EXPRESS. The results show that it is possible to make the desired calculations about the house with EXPRESS. The definition made with a project that is still in the design phase can determine whether the project provides the desired spatial conditions by making any calculations. Thus, quality and cost-effective projects can obtain. Keywords: EXPRESS; housing; BIM; ISO 10303
\end{abstract}

eISSN: 2398-4287 @ 2019. The Authors. Published for AMER ABRA cE-Bs by e-International Publishing House, Ltd., UK. This is an open access article under the CC BYNC-ND license (http://creativecommons.org/licenses/by-nc-nd/4.0/). Peer-review under responsibility of AMER (Association of Malaysian Environment-Behaviour Researchers), ABRA (Association of Behavioural Researchers on Asians) and cE-Bs (Centre for Environment-Behaviour Studies), Faculty of Architecture, Planning \& Surveying, Universiti Teknologi MARA, Malaysia.

DOI: https://doi.org/10.21834/e-bpj.v4i11.1738

\subsection{Introduction}

"Recent developments in robotics, artificial intelligence, and machine learning have put us on the cusp of a new automation age. Robots and computers can not only perform a range of routine physical work activities better and more cheaply than humans, but they are also increasingly capable of accomplishing activities that include cognitive capabilities once considered too difficult to automate successfully, such as making tacit judgments, sensing emotion, or even driving. Automation will change the daily work activities of everyone, from miners and landscapers to commercial bankers, fashion designers, welders, and CEOs."

Report of McKinsey Institute

Building Information Modeling (BIM) is a system that can be used effectively in all processes in projects. The aim is to increase the quality and speed of interdisciplinary communication and to provide the most suitable product to the end-user. Therefore, the use of BIM in construction makes the sector more efficient, effective, flexible, and innovative.

To know to what extent the architectural projects provide comfort conditions requires long-term and demanding calculations. This paper describes how to use the EXPRESS language for the definition of a structural product. In the design phase, a housing structure modeled with BIM-based software defined with EXPRESS language. In this way, the calculations are done with the design phase of the desired construction of the housing structure to ensure the desired spatial conditions can obtain quickly and accurately the desired results.

In the scope of this research, firstly literature review was done - the concept of EXPRESS standard and the ISO 10303 standards required for the developed model reviewed. The information obtained from the literature review tested with the applications made within the scope of the research. Definitions required for housing structure investigated - visual presentation algorithm created with EXPRESS-G. A sample project with BIM-based software designed and integrated with the visual presentation created.

The project incorporated with the EXPRESS-G visual presentation and the parameters related to the current state of the project can test with the application. When these parameters examined, it can determine whether the project meets the requirements.

eISSN: 2398-4287 (C) 2019. The Authors. Published for AMER ABRA cE-Bs by e-International Publishing House, Ltd., UK. This is an open access article under the CC BYNC-ND license (http://creativecommons.org/licenses/by-nc-nd/4.0). Peer-review under responsibility of AMER (Association of Malaysian Environment-Behaviour Researchers), ABRA (Association of Behavioural Researchers on Asians) and cE-Bs (Centre for Environment-Behaviour Studies), Faculty of Architecture, Planning \& Surveying, Universiti Teknologi MARA, Malaysia.

DOI: https://doi.org/10.21834/e-bpj.v4i11.1738 
The overall architectural planning processes are no longer carries out linearly, but instead in a complex and integrated manner, therefore it seems that classical methods cannot support these processes efficiently. This study is also an effort to strengthen the competitiveness of the building industry by improving planning reliability, quality, and efficiency.

\subsection{BIM Concept}

In most new building projects, design teams work collectively in a shared BIM (Building Information Modelling) model. It offers many opportunities to use BIM technologies as a platform to exchange and record design preferences and decision criteria. It is particularly useful during the early design stages when different design options investigate.

BIM for Building Information Modelling is a concept that appeared in the middle of ' 90 s. The idea of BIM is to integrate all building information in one only theory. Although the name initially found by Autodesk, it used by other software developers such as Graphisoft and Nemetschek.

BIM (Building Information Modeling) defined in three terms in the glossary of words developed by the IAI.

1) To provide a shared parametrical presentation of the physical and functional characteristics of a structure built on open standards for interoperability,

2) A shared source of information about the building, which forms a safe basis for decision-making throughout the life cycle of the building,

3) The primary purpose of the partnership is cooperation between different partners in the stages of the life cycle of the structure, which is to add, subtract, renew and change the information in a way to support roles of partners.

Many countries, mainly Northern European countries, have developed their standards of BIM. "National BIM Standards" (NBIMS, 2008 ) in the USA, "building SMART" (NO 2008) in Norway, "CRC Construction Innovation" (CRC Cl 2008) in Norway, DK (DK 2008) in Denmark are among the best- known national BIM standards.

It is defining BIM as software type reduces its importance for design and construction processes. Eastman et al. (2011) state that it is necessary to understand BIM as a wide range of concepts, activities, techniques, tools, and subjects united in complex relationships and distributed in all activities related to the construction industry.

By using BIM technology, the designer, "build" virtually a building model through objects that simulate the behavior and shape of constructive elements. The virtual models can understand as databases, where stored both geometric data and text information of each construction element used in the design. The combination of this data enables the automatic extraction of documents such as plans, sections, perspectives, and quantities to take off (Brix, 2006).

The usage of BIM in Architecture, Engineering, and Construction (AEC) sector has been increasing rapidly. The concept of BIM contains the formation and the usage of the design, construction, and management knowledge of buildings. The computational model of BIM forms an environment that serving the various disciplines of the design process to work together (Turkyilmaz, 2013).

$\mathrm{BIM}$ is the use of the computer-generated model to simulate the planning, design, construction, and operation of a facility. It is a technology that allows users to create a visual simulation of a project with a digital prototype of a building before construction. The deployment of BIM in construction can make the industry more efficient, effective, flexible, and innovative (Takim et al., 2013).

BIM is a digital database that contains physical and functional data of the project (Reddy, 2012). BIM provides effective cooperation, visual representation, and data management, enabling a smooth flow of information throughout the life cycle of the project (Georgiadou, 2016). BIM creates a new paradigm and works environment by integrating whole stakeholders of the construction sector. This integration has the potential to achieve greater efficiency and interoperability between stakeholders who see themselves as adversaries in traditional ways of working (Azhar, 2011).

BIM foresees that the information retrieved from paper documentation that can be easily lost passed through a standardized, sustainable and developed a common digital model (Building Information Model), stored and used throughout the life of the building. According to Eastman (2011), BIM is one of the most promising developments that allow the creation of one or more virtual digitally generated models of a building to support the design, construction, manufacturing and purchasing activities of the building.

BIM applications have gained a lot of attention in various structural engineering operations (program improvements, cost estimations, data documentation and interoperability, design team communication), as reported in an extensive review by Eleftheriadis et al. (2017). Today, the construction sector is experiencing rapid change and development. Complex structures require a consistent and sustainable flow of information during both design and application. The importance of collaboration with cost and time factor increases in the implementation of these buildings. Disruptions in the flow of information prevent the formation of collaboration and cause a decrease in productivity.

BIM provides an interdisciplinary exchange of information between architects, engineers, employers, and contractors in a threedimensional environment. It is an information management system that extends from the first design process of the structure to the usage phase of the building after the construction phase and after (Dispenza, 2010).

For each project, BIM can be used in all stages of planning, design (pre-fabrication), construction and operation (post-production). Table 1. shows the use of BIM during the structure lifecycle. 
Table 1: Use of BIM throughout the structure life cycle

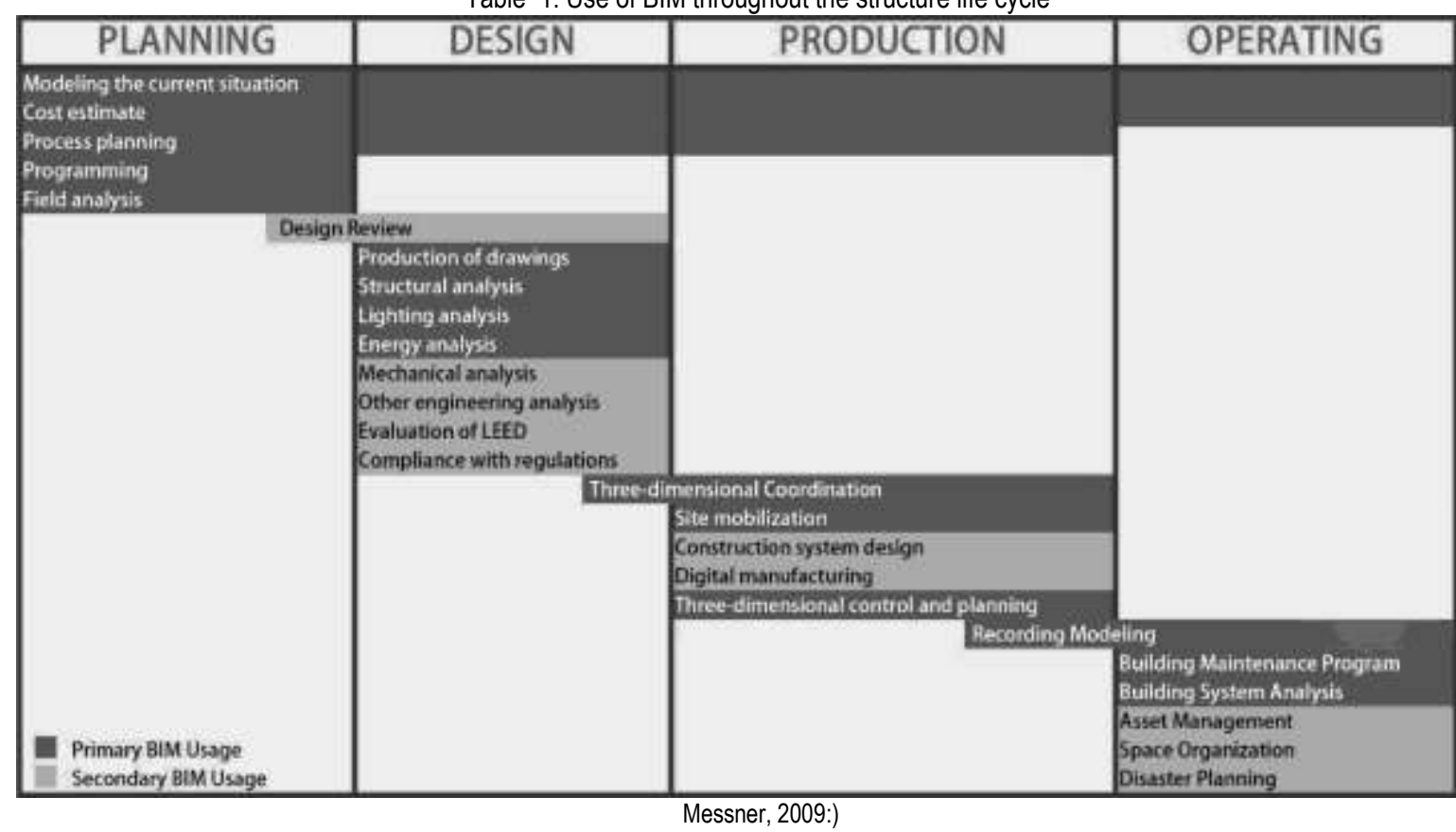

\subsection{BIM in the Planning Process}

$\mathrm{BIM}$, which provides a healthy foundation for the decisions to be taken within the process from the design stages to the demolition, is not only the 3D model of the project, but also stores the digital data of the project before the production, presents the model analyzes, is a source of information that all stakeholders benefit from and can share (Muratoğlu, 2015). With BIM model, net and gross areas of the floors, volumes, material quantities and area usages, building cost calculations, structural analyzes, energy performance, acoustics, lighting, and thermal analyzes, fire, heating and cooling analyzes can do easily (Reddy, 2011).

\subsection{BIM in Design Process}

The use of BIM in the design phase can best show its impact on the project. BIM allows for the production of complex structures in a shorter period, and repetitive structures can form by formulas and parameters (Eastman et al., 2011). BIM provides the ability to predict the cost of the project during the design phase. Also, BIM plays an essential role in ensuring the cooperation and coordination of interdisciplinary participants in the whole project process. The use of BIM strengthens the joint efforts of the team in particular. Architect and engineer can test design ideas, including energy analysis, construction, sorting, value, and engineering reports.

\subsection{BIM in Construction Process}

Working with BIM; it provides less repetition, fewer change requests, fewer order changes, pre-construction detection of design errors, and the ability to build systems with less skilled labor. Contractors and other project participants can obtain information about the construction and manufacturing issues at the early stage of design, thus ensuring the design's constructability. Code compliance, feasibility studies, accurate quantity, and site planning can make them more accurately. With BIM, construction of the structure can achieve in the most appropriate way to the targeted time plan (Muratoğlu, 2015).

\subsection{BIM in the Use and Operation}

In the life cycle of buildings, the design and construction phases, as well as the operation and maintenance phases, are of great importance. Because the work of the building in the building sector is the main contribution of the cost of the plant life of the building phase and $85 \%$ of the life cycle costs of the building realize after the construction, two-thirds of the estimated cost is lost in the US due to inefficiency between the cooperation, operation and maintenance phases (Lee) et al., 2012; Jordani, 2010; Rundell, 2006).

Research has gained importance since the emergence of BIM processes and the fact that BIM information captured throughout the life cycle of plants can help facility management (FM) increase efficiency (Kelly et al., 2013). While BIM has an active role in the design and construction of buildings, its adaptation in the facility management (FM) phase has been more in the background (Teicholz, 2012).

\subsection{EXPRESS}

EXPRESS is the data modeling language for product information. With EXPRESS, the data model can define in two ways: written and visual. The written EXPRESS-G is for visual representation, and EXPRESS-G is for visual representation. EXPRESS describes different data types together with algorithmic rules in a schema. EXPRESS-G is used to visually display assets and genre definitions, relationships, and clusters. 
The main elements of EXPRESS are schema, type, asset, and rule. EXPRESS, as a whole, is a complicated language and firstly, after learning the basic principles, it goes to high-level knowledge.

EXPRESS breaks down the information modeling problem. For a collection of related definitions, a wrapper provides a way to express description of a unit of information and a way to represent value fields. The wrapper schema is called the information unit, the entity, and a value is called the domain data type. It turns out that an asset can be a data type when we want it to be.

The International Standards Society has developed EXPRESS for information modeling by defining the information needed to design, build, and maintain products. It represents a subset of the textual form, it is an officially designated structured language, together with a sample language called EXPRESS-I, to illustrate a defined graphical language called EXPRESS-G and how the values of entity declarations can write. The basic structures are "entity" and "attribute." An example EXPRESS model shown below.

SCHEMA project_team;

ENTITY project_team;

ABSTRACT SUPERTYPE OF (OneOf(architect,construction_engineer,mechanical_engineer,

electrical_engineer)

END_ENTITY;

ENTITY architect;

SUBTYPE OF (OneOf(project_team);

END_ENTITY;

ENTITY construction_engineer;

SUBTYPE OF (OneOf(project_team);

\section{END_ENTITY;}

ENTITY mechanical_engineer;

SUBTYPE OF (OneOf(project_team);

\section{END_ENTITY;}

ENTITY electrical_engineer;

SUBTYPE OF (OneOf(project_team);

\section{END_ENTITY;}

END_SCHEMA;

The above data scheme includes the project team super type unit, which includes sub-species architect, civil engineer, mechanical engineer, and electrical electronics engineer. The units that are the sub-types of the project team can play an active role in the project team as well as separately.

EXPRESS-G is the standard visual representation for information models. It is used to visually display assets and species definitions, relationships, and clusters. EXPRESS-G supports part of the EXPRESS language. One advantage of using EXPRESS-G instead of EXPRESS is that the structure of the data model can show more understandably. One disadvantage of EXPRESS-G is that complex constraints cannot be formally specified (Schenck and Wilson, 1994).

An entity defines a set of attributes. A property specifies a data type (and therefore a domain) and a severity level. A data type, number, real, string, etc. a language such as a principal, or an entity (refer to another entity). The names of the attributes represent the relationship between the assets in the entity data type or the fields of qualifications. Business or requirements (and relationships) can be further defined or refined by restrictions written in the form of a procedural language. Supertype/subtype hierarchies support by the constraints of the allowed types of subtypes. EXPRESS does not require a methodology and is not restricted to normalization, although models can be typed usually if desired. EXPRESS models are typically object-oriented models. The formatting language often explained by structured descriptive text (Figure 1.).

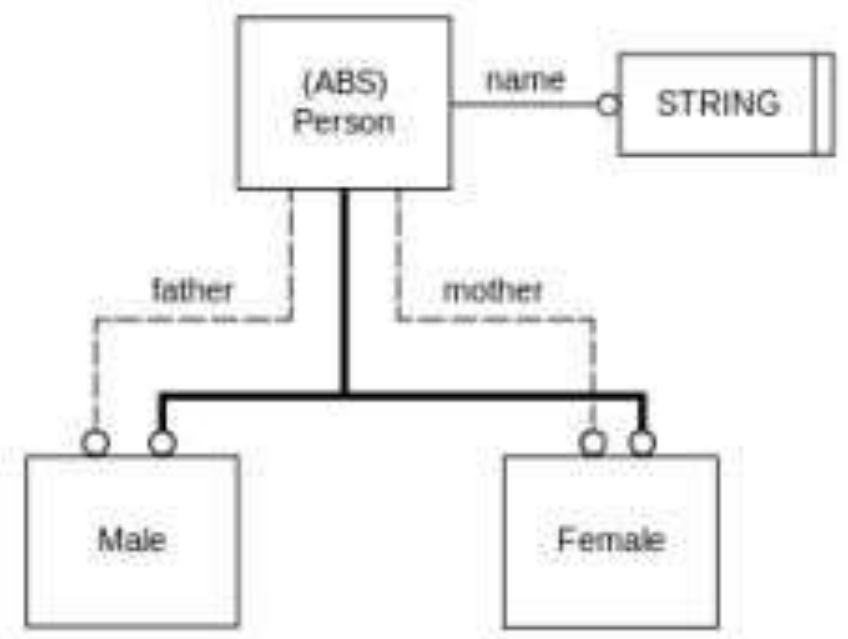

Fig. 1: An EXPRESS-G representation for the Family Schema (Türkyılmaz, 2010) 


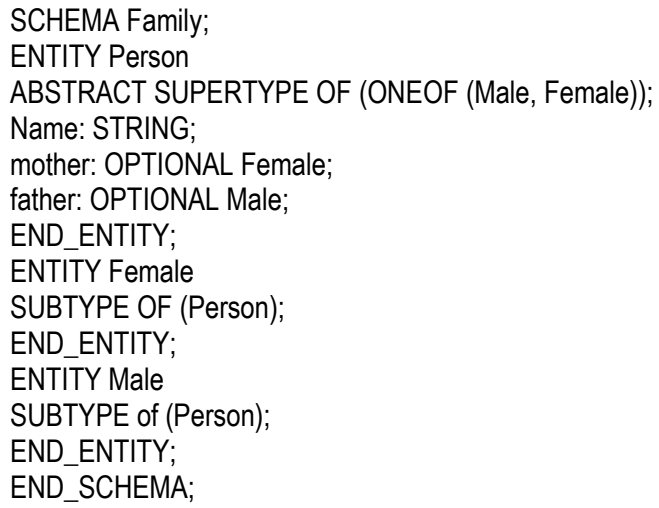

The above data scheme includes the Human super type unit, which contains two subspecies, Male and Female. Since the human being indicates as ABSTRACT, subspecies may be only one of Male and Female (ONEOF). Man has all the states, the mandatory name attribute, and the optional mother and father attribute. Some volume types have a fixed reading for attributes. Also, there are the following:

- A Woman can play the Mother for Man role,

- A Man can play the Father for Man role.

\subsection{Proposed Model}

This study deals with the definition of an architectural product with EXPRESS language. To be able to make this definition, the description of the housing project in Figure 2 and the EXPRESS-G notation in Figure-3 were made. A housing project in Figure 2 modeled in 3D. This plan examined in EXPRESS language and the necessary information collected for the definition of housing. This information made into a table with the visual presentation EXPRESS-G. In this visual table, the parameters and subdivision areas for an apartment building with residential apartments shown. These areas designated as compulsory and non-compulsory areas. For example; the technical space is mandatory for an apartment building while the recreational area is non-compulsory. The parameters required for each field are also processed.

The parameters defined for the sub-type housing structure and the required fields processed in the same way. Although there are mandatory and non-compulsory areas within the housing structure, the number of spaces may also vary. While the bedroom is a compulsory area for housing, WC defines a non-mandatory area. The numbers of these areas may vary.

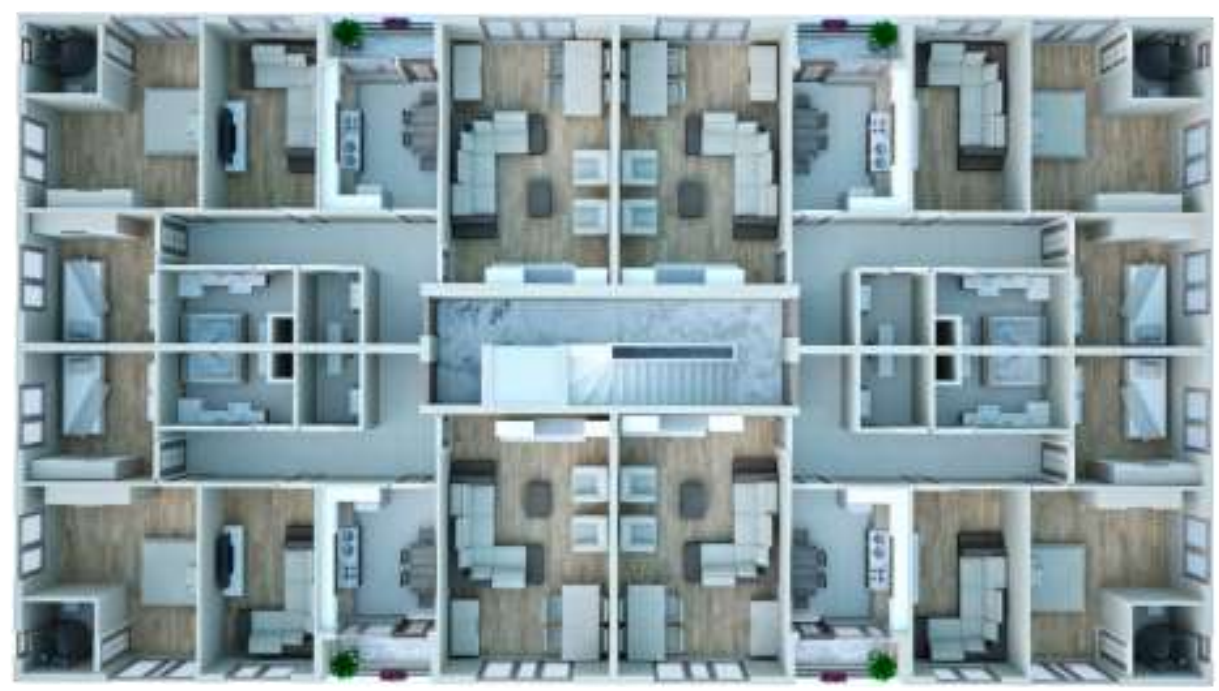

Figure 2. 3D Housing project 


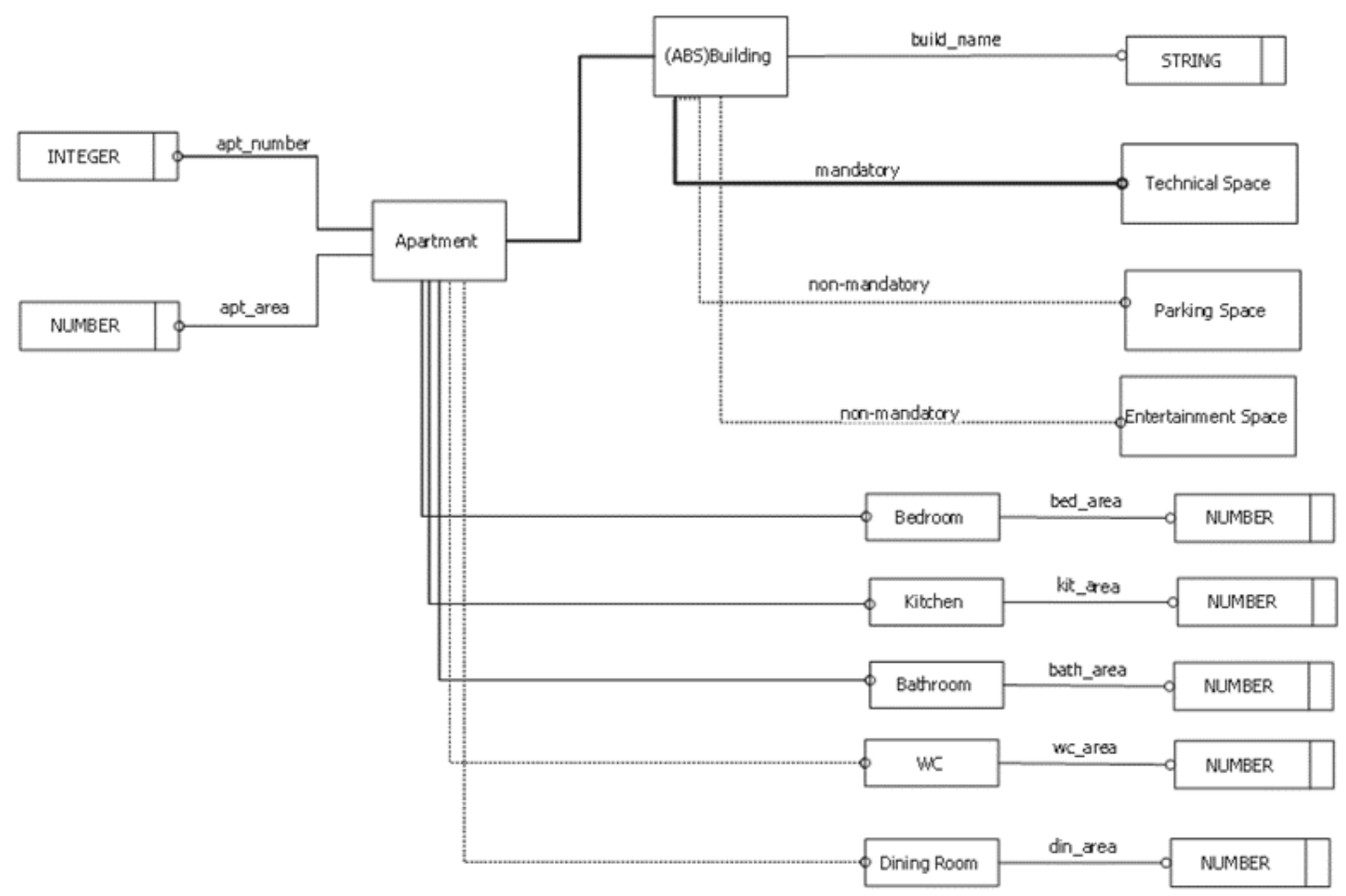

Figure 3. The EXPRESS-G notation of Figure-2

\subsection{Conclusion}

This study is intended to provide a perspective of the design process in a more collaborative, integrated, and efficient way within the light of BIM framework. In architectural design processes, long-term and challenging calculations are required to learn to what extent architectural projects provide comfort conditions. Architectural planning processes cannot be carried out directly and are carried out in a complex and integrated manner. Therefore, the resulting product is insufficient in terms of time, cost, and quality. The dynamic and financial strength of the construction sector is connected to productivity and management.

In order for the firms operating in the architecture, engineering and construction sector to distinguish themselves from the competition in the national and international arena by creating a difference and awareness; projects should be able to minimize time and cost losses, increase quality of life, produce more sustainable projects, use energy and resources more effectively and efficiently, and should be able to cooperate effectively among all stakeholders in the project process. Companies need to adapt to developing and advancing technology and the innovations that come with technology.

BIM's goal is to ensure the cooperation between the disciplines in the project and to manage all the information required from the design of the project to the production process and to provide the positive feedback and full utilization of the opportunities it offers. It will be possible with effective use of BIM applications.

In this study, the EXPRESS language integrated with BIM concept and the expression of a housing project explained with EXPRESS$G$ notation. The projects created with EXPRESS language formed by constructing more systematically. In this way, process planning, quality, safety, and efficiency will ensure. In this way, the products that will be created by controlling the projects while they are still in the concept project will be formed more healthy.

All kind of design approaches and technologies may not resemble tomorrow. Tools and techniques may change, evolve, and new design systems may emerge. Some of the issues mentioned and emphasized in this study may also lose their reality, correctness, or applicability in the future. The important thing is to be able to stay up to date and change in an adaptive way in the developing world.

\section{References}

Azhar, S. (2011). "Building information modeling (BIM): Trends, benefits, risks, and challenges for the AEC industry. Leadership and Management in Engineering", 11(3), 241-252.

Atay, G. F.,(2011), "Mimari Üretimde Kullanıının Yeri," Yayımlanmamış Doktora Tezi, MSGSÜ FBE, İstanbul (in Turkish)

Atkin, B., \& Brooks, A. (2014). Total facility management. Chichester, West Sussex, United Kingdom: John Wiley \& Sons Incorporated.

Barnes, P., \& Davies, N. (2014). BIM in Principle and in Practice. London: ICE Publishing. 
Birx, G W.(2006), Getting started with Building Information Modeling. The AIA-Best Practices.

Björk, B.C. (1995). Requirements and Information Structures for Building Product Models. Helsinki, VTT Technical Research Center of Finland.Cotts, D., Roper, K. O., and Payant, R. P. (2009). The facility management handbook. New York, NY: AMACOM.

Czmoch, I., \& Pękala, A. (2014). Traditional Design versus BIM Based Design. Procedia Engineering, 91, ss. $210-215$.

Dispenza, K. (2010). The Daily Life of Building Information Modeling (BIM), http://buildipedia.com/in-studio/design-technology/the-daily-life-ofbuildinginformationmodeling-bim

Eastman C. et al., (2011), BIM handbook: A guide to building information modeling for owners, managers, designers, engineers, and contractors, Hoboken-Wiley; 2011, $490 \mathrm{p}$.

Eleftheriadis S., Mumovic, D., Greening, P. (2017). Life cycle energy efficiency in building structures: a review of current developments and future outlooks based on BIM capabilities, Renew. Sustain. Energy Rev., 67, pp. 811-825

Georgiadou. M.C. (2018), Building Information Modelling enters mainstream UK construction market. In RICS. RICS.

Türkyılmaz, E. (2010). "Ifc Veri Modeline Dayalı Kavramsal Bir İşbirliği Ortamı” Yıldız Teknik Üniversitesi Fen Bilimleri Enstitüsü, İstanbul (in Turkish)

Kelly, G., Serginson, M., Lockley, S., Dawood, N., \& Kassem, M. (2013). BIM for Facility Management: A review and case study investigating the value and challenges, Proceedings of the 13th International Conference on Construction Applications of Virtual Reality, Teesside University, 30-31 October, 191.

Lee, S., An, H., \& Yu, J. (2012). An Extension of the Technology Acceptance Model for BIM-Based FM. Construction Research Congress, 602-611.

McKinsey Global Institute Report (2017). Harnessing automation for a future that works

Miettinen, R., \& Paavola, S. (2014). Beyond the BIM utopia: Approaches to the development and implementation of building information modeling. Automation in Construction 43 , ss. $84-91$.

Muratoğlu, H. (2015). BIM Kullanımının Tasarım Aşamasından Kaynaklanan Uyuşmazlıkları Üzerine Etkileri, Yüksek Lisans Tezi, Fen Bilimleri Enstitüsü, İ.T.Ü, Mimarlık Anabilim Dalı, İstanbul (in Turkish).

Reddy, K. P. (2012). BIM for building owners and developers: making a business case for using BIM on projects. Vasa.https://doi.org/10.1017/CBO9781107415324.004

Rundell, R. (2006). How can BIM benefit facilities management? Primeedge.Retrieved from http:// www.cadalyst.com/cad/building-design/1-2-3-revitbim-andfm-3432

Schenck D., \& Wilson P. (1994). "Information Modeling the EXPRESS Way” Oxford University Press, Inc.,200 Madison Avenue, New York, New York 10016.

Takim, R., Harris, M., Nawawi, A. H. (2013). Building Information Modeling (BIM): A new paradigm for quality of life within Architectural, Engineering, and Construction (AEC) industry. Procedia - Social and Behavioral Sciences, 101, 23-32.

Taşlı, Ş. (1998). A Commentary Bibliography: Knowledge Representation for Architectural Systems, http://www.art.bilkent.edu.tr/iaed/cb/Tasli.html (6 Ocak 2009).

Turner John F. C., Fichter, Robert, (1972), "Freedom to Build: Dweller Control of the Housing Process," The Macmillan Company, New York

Türkyılmaz, E. (2013). "A proposal for energy-efficient design: An IFC based design decision system and its application," Eighth International Conference on Urban Regeneration and Sustainability-Sustainable City 2013, 3-5 December 2013, Putrajaya, Malaysia, Proceedings book, 663-671.

Teicholz, E. (2012). Technology for Facility Managers: The Impact of Cuttingedge Technology on Facility Management. John Wiley \& Sons

Volk, R., Stengel, J., \& Schultmann, F. (2014). Building information Modeling BIM for existing buildings- Literature review and future needs. Automation in Construction, 38, 109-127 